\title{
Sedimentary Facies of the Chang 2 Member of Yanchang Formation in Area A of Northern Shaanxi
}

\author{
Yingzhi Liu ${ }^{1}$, Yanyan Liu ${ }^{2}$, Ying Chen ${ }^{1}$, Shasha Yang ${ }^{3, *}$ and Bowang Wang ${ }^{3}$ \\ ${ }^{1}$ Zhidan Oil Production Plant, Shaanxi Yanchang Petroleum (Group) Co. Ltd., Yan'an, Shaanxi, 716000, China \\ ${ }^{2}$ Changqing Downhole Technology Operation Company, CNPC Chuanqing Drilling Engineering Co.Ltd., Xi'an, Shaanxi , 710018, China \\ ${ }^{3}$ Shaanxi Key Laboratory of Safety and Durability of Concrete Structures, XiJing University, Xi'an, Shaanxi, 710123, China
}

\begin{abstract}
In order to promote the rolling exploration and development of oil reservoirs in northern Shaanxi, a fine study of sedimentary facies in area A has been carried out. Using core and logging data, on the basis of identifying different levels of sequence interfaces and lake flooding, the Chang 2 Member in Area A was divided into two base level cycles, and a high-resolution sequence stratigraphic correlation was established. On the basis of core description, the analysis of single-well sedimentary facies, continuous-well sedimentary facies and planar sedimentary facies are carried out. It is believed that the Chang 2 member of the study area is a delta plain deposit, dominated by distributary channels, inter-distributary depressions, and natural dike microfacies. There are two to three main rivers in the study area. Both the vertical and the plane show that the length of Chang $2_{2}$ sand bodies is more developed than the length of Chang $2_{1}$ sand bodies. Among the three small layers of Chang 22 , Chang $22_{2}{ }^{1}$ sand body is relatively well developed, and the channel width and thickness are large, making it the most favorable reservoir.
\end{abstract}

\section{Introduction}

The Ordos Basin is the second largest basin in China. The Triassic Yanchang Formation in the basin made a major breakthrough in the early stage of exploitation, and has been the main target layer for oil and gas exploration ever since. According to sedimentary cycles, paleontology, lithology and other characteristics, the Yanchang Formation is divided into 10 oil-bearing groups from top to bottom, of which Chang 2 is the main oil-bearing series of the basin[2-4]. By the Chang 2 stage, the plain facies or plain distributary channels developed, the lake basin had shrunk, and the sedimentation was strengthened to form a set of sand-rich sediments[5,6]. Area A is located in the middle-eastern part of the northern Shaanxi slope of the Ordos Basin. The Chang 2 oil layer group is the main oilbearing series of the northern Shaanxi slope, but the development effect in recent years has not been satisfactory. Therefore, it is necessary to study in detail the sedimentary characteristics of the Chang 2 reservoir and its sand body distribution characteristics [7].

Area A is located in the northern Shaanxi area of the Ordos Basin. The landform of this area is classified as the landform of the northern Shaanxi Loess Plateau. The flat top is wide, and the surrounding valleys are cut. The ground elevation is about $1.1 \sim 1.35 \mathrm{~km}$, and the height difference is about $150 \sim 250 \mathrm{~m}$. The regional tectonic unit in the study area belongs to the middle-eastern part of the northern Shaanxi slope of the Ordos sedimentary basin. The general structural pattern of the Chang 2 oil layer group in the eastern part of the northern Shaanxi slope is a large, gentle monoclinic with gentle tectonic activity and a small dip angle. As a result of compaction, a series of low-amplitude nose-like uplifts that dip from east to west develop on the slope belt [8].

\section{The distribution of sedimentary microfacies and sand bodies}

\subsection{Types of sedimentary facies in the study area}

Sedimentary facies is a combination of the sedimentary environment and the characteristics of the sedimentary rocks formed in the environment. Since the depositional conditions are the material basis for the formation of reservoirs, the formation of a good reservoir must have favorable sedimentary facies belts. Sedimentary facies not only determine the production status of the reservoir, including the horizon, reservoir cap conditions, reservoir scale and distribution form, but also determine the internal structure and rock type of the reservoir, thereby controlling the distribution of oil and gas.

Area A is located in the middle-south section of the Yishan Slope, which is the broadest in the Ordos Basin, and is one of the main areas for oil exploration and development in the basin. According to previous research results, with reference to the regional sedimentary background, combined with actual data, a comprehensive analysis of the Chang 2 oil layer group of the Yanchang Formation in the A area is a delta plain sedimentary system.

* Corresponding author: 20190100@xijing.edu.cn 
The delta plain sedimentary environment and sedimentary characteristics have many similarities with fluvial facies. Due to the flat terrain of the delta plain area, a large number of bifurcated river channels, small river energy, shallow water depth, and relatively large width of the distributing channel, the grain size of the sediments is small and the separation is good. The lithology is mainly sandstone and silt and mudstone. At the same time, due to the flat and humid terrain in the plain area, the vegetation is relatively developed. There are many plant rhizomes and plant fragments in the sediments, and sometimes thin coal seams can be seen. The delta plain is composed of distributary channels, depressions between distributaries, and natural dikes. The distributary channels and channels constitute the main body of the study area. The division of the microfacies is shown in Table 1.

Table 1. Sedimentary facies division table of Chang 2 in area A

\begin{tabular}{|c|c|c|}
\hline $\begin{array}{c}\text { Sedimentary } \\
\text { facies }\end{array}$ & $\begin{array}{c}\text { Sedimentary } \\
\text { subfacies }\end{array}$ & $\begin{array}{c}\text { Sedimentary } \\
\text { microfacies }\end{array}$ \\
\hline \multirow{2}{*}{ Delta } & & Diversion channel \\
\cline { 3 - 3 } & Delta plain & $\begin{array}{c}\text { Depressions } \\
\text { between diversions }\end{array}$ \\
\cline { 3 - 3 } & & $\begin{array}{c}\text { Natural } \\
\text { embankment }\end{array}$ \\
\hline
\end{tabular}

\subsection{Sedimentary microfacies in the study area}

\subsubsection{Diversion channel}

The distributary channel deposition is the skeleton part of the delta plain facies, which has the characteristics of general channel deposition. It is mainly fine-grained feldspar sandstone, with a small amount of siltstone and argillaceous siltstone, sorted, etc. On the plane, it is pointed and belt, strip-like distribution, lenticular in the section, with many scour surfaces at the bottom, containing mud and gravel. Sedimentary structures can be seen in various cross bedding such as groove cross bedding, plate cross bedding, parallel bedding, etc., On the vertical the thinning sedimentary sequence shows a positive rhythm.

\subsubsection{Depression between diversions}

Depression between diversions refer to the storage depressions behind the banks of distributary channels and between adjacent distributary channels. In low-lying water-rich places, lush vegetation can form marsh deposits, which are the limited environmental deposits between distributary channels. The depressions and swamps between the diversions are the "body" of the delta plain subfacies. The microfacies of the inter-distributary depressions are mainly formed by the cross-bank deposition of fine suspended matter carried by the river. It is dominated by dark gray and brown gray mudstone with a small amount of fine sand and silt deposits. Horizontal bedding is seen in the mudstone, and plant fossil fragments are often preserved. The natural gamma curve has a high-value micro-tooth shape.

\subsubsection{Natural embankment}

Natural embankments are developed on both sides of the distributary channel. When the flood overflows out of the riverbed during the flood, the suspended silt and fine sand are deposited on both banks of the channel. The main lithology is fine siltstone interbedded with mudstone or interbedded with thin mudstone. The grain size becomes finer as the distance away from the river channel, and the mudstone increases. Wave-like bedding, sand-line bedding and climbing laminae, horizontal bedding are common, and plant roots, stems and plant fragments can be seen. The natural gamma curve is generally a lowamplitude toothed clock Shape, box shape.

\subsection{Single-well facies analysis in the study area}

Based on the classification of sedimentary facies and the characteristics of sedimentary microfacies, in order to reveal the law of vertical evolution and planar distribution of sedimentary facies in the Chang 2 oil layer group in the study area, a single-well sedimentary facies analysis was carried out on two wells in the study area.

(1) B95 single well facies analysis

B95 is located in the northwest of the study area. The distributary channels, interdistributary depressions and natural dike microfacies frequently overlap each other in the bottom-up delta plain. Chang $22_{2}^{3}$ mainly develops distributary channel microfacies, Chang $2_{2}{ }^{2}$ develops interchannel microfacies, and Chang $2_{2}{ }^{1}$ sand The thickest body, the curves are mostly box-shaped, and distributive channel microfacies are also developed. In comparison, the long $21^{3}$ and long $21^{2}$ curves are mostly positive anomalies, and the microfacies between the channels are relatively developed, and the lower part of the long $2{ }_{1}{ }^{1}$ develops a distributive channel, The microfacies between the river channels are developed in the upper part.

(2) D116 single well facies analysis

D116 is located in the middle of the study area. The distributary channels, interdistributary depressions and natural dikes in the delta plain from the bottom to the upper are micro-overlapping and inter-channel microfacies. The lower part of Chang $22^{3}$ develops distributary channel microfacies, and the upper part of Chang $22^{3}$ to the middle part of Chang $22^{2}$ develops interchannel microfacies. From the middle of Chang $2_{2}{ }^{2}$ to the top of Chang $22_{2}{ }^{1}$, the curves are mostly box-shaped, and distributary channel microfacies are also developed. In comparison, the long $21^{3}$ curves are mostly positive anomalies, and the microfacies between the channels are relatively developed, ranging from $21^{2}$ to long $21^{1}$. The development of distributary channel microfacies.

\subsection{Analysis of the connected profile of the sand body in the study area}

Profile facies analysis is based on the analysis of single well sedimentary facies, making full use of electrical logging data for comparison, establishing the phase 
sequence relationship between adjacent wells, and determining the distribution characteristics of sedimentary facies in two-dimensional space.

Combining the structural location and geological evolution background of the study area, based on a large number of exploration and development practices, two continuous well profiles that can reflect the sedimentary facies of the area have been established. The two sections show that the Chang 2 formation is not undulating. The sand bodies of Chang $21^{1}$ and Chang $22^{1}$ are the best developed, with a thickness of more than $10 \mathrm{~m}$, and the sand bodies have good connectivity. Chang $2{ }_{1}{ }^{1}$ develops a set of thicker sand bodies, while Chang $21^{1}$ and Chang $2{ }_{2}^{1}$ are several sets of sand bodies superimposed on each other. The Chang $22_{2}^{3}$ sand body is well developed, with an average thickness of about $6 \mathrm{~m}$, and the sand body has good connectivity. Only small lenticular sand bodies develop in other small layers.

\subsection{Sedimentary microfacies and distribution characteristics of sand bodies}

The study of the planar characteristics of sedimentary microfacies is an important geological basis for reservoir development and analysis. It is a key step in the study of reservoir heterogeneity and remaining oil distribution. It is also the main purpose of microfacies research. It is restricted by a series of factors, including Factors such as paleo-climatic conditions, source area direction and paleotopographic features, as well as the development status and energy of river systems. On the basis of determining sedimentary facies, subfacies, and microfacies, following the point-line-plane research method, starting from the single-well facies diagram analysis, the well facies diagram analysis is connected again, and finally the sedimentary microfacies of the target layer in the study area is carried out. Accurate analysis and summary of phase plane characteristics.

During the Chang 2 deposition period, the sediments in the study area mainly came from the northeast, and the delta plain distributary channel was dominant, and two large sedimentary cycles developed, namely Chang $2_{2}$ and Chang $2{ }_{1}$, of which the distributary channel of Chang $2_{2}$ was more developed, and the sand bodies were distributed close to each other. Northeast-southwest direction, and the distributary channel of Chang $2_{1}$ is not as well developed as that of Chang $2_{2}$. Three secondary cycles developed in the Chang $2_{2}$ period, namely Chang $22^{3}$, Chang $22_{2}^{2}$, and Chang $22_{2}{ }^{1}$. The role of the distributing channel from the lower sedimentation is strong, and it gradually changes upwards. It is mainly composed of inter-channel sedimentation, and then develops into distributive channel upwards. During the Chang 21 period, three secondary cycles were also developed, namely Chang $21^{3}$, Chang $21^{2}$ and Chang $2{ }_{1}{ }^{1}$, which were deposited between the lower channels and gradually became dominated by distributary channel deposits upward. By drawing the sedimentary microfacies plane distribution map and sand body thickness contour map of each small layer of the Chang 2 oil layer group in this area, some understanding of the sedimentary microfacies and sand body distribution characteristics of each small layer of the Chang 2 oil layer group in this area can be obtained. Two representative sublevels are selected below.

(1)Distribution characteristics of Chang $22_{2}^{1}$ sedimentary microfacies and sand bodies

The Chang $2{ }_{2}^{1}$ period also continued the development of the lower strata. Three main channels developed in the study area, extending from northeast to southwest. In plane, these three diversion channels flow in from the northeast direction, and flow out from the southwest direction and the south direction. Among them, the channel in the middle of the study area is the best developed, with a channel width of up to $550 \mathrm{~m}$, the channel in the northwest of the study area is well developed, with a width of about $510 \mathrm{~m}$, and the channel in the southeast of the study area is the worst developed, with a width of about $240 \mathrm{~m}$, at K36 There are two distributary channels developed at the well, and the thickness of the sand bodies of the three main channels in this small layer are all above $15 \mathrm{~m}$.

(2)Distribution characteristics of Chang $2{ }^{1}$ sedimentary microfacies and sand bodies

In the Chang $2{ }_{1}^{1}$ period, delta plain deposits were still developed, and three main river channels were developed in the study area, extending from northeast to southwest. In plane, these three diversion channels flow in from the northeast direction, and flow out from the southwest direction and the south direction. Among them, the channel in the middle of the study area is the best developed, with a channel width of up to $740 \mathrm{~m}$, the channel in the southeast of the study area is well developed, with a width of about $700 \mathrm{~m}$, and the channel in the northwest of the study area is the worst developed, with a width of about $510 \mathrm{~m}$. The thickness of the sand bodies of the three main channels of the layer is more than $10 \mathrm{~m}$.

\section{3 summary}

1. The Chang 2 stratum in the study area is mainly composed of delta plain deposits controlled by provenance in the Northeast, with distributary channels, interdistributary depressions and natural dike microfacies. Each sub-layer develops two to three main channels in the study area.

2. Vertically, the two sedimentary cycles of Chang $2_{2}$ and Chang 21 all started with the development of distributary channels. Among them, the sand body of Chang $2_{2}$ is more developed than that of Chang $2_{1}$. Among the three small layers of Chang 22 , the Chang $2_{2}{ }^{1}$ sand body is the best developed. The sand body of the channel is more than $15 \mathrm{~m}$ thick, and the Chang $22^{3}$ sand body is well developed. The sand body of the channel is more than $10 \mathrm{~m}$ thick.Chang $22^{2}$ sand body is the worst developed. Among the three small layers of Chang $2{ }_{1}$, the Chang $2{ }_{1}^{1}$ sand body is the best developed, and the sand body thickness of the channel is more than $10 \mathrm{~m}$. In comparison, the Chang $21^{3}$ and Chang $21^{2}$ sand bodies are poorly developed, and the sand body thickness of the channel is greater than $6 \mathrm{~m}$.

3. On the plane, the sand body of Chang $2_{2}$ is more developed than Chang $2_{1}$, and the channel width is larger. 
In the three small layers of Chang 22 , Chang $2_{2}{ }^{1}$ sand bodies are relatively well developed, with a channel width of $550 \mathrm{~m}$, and Chang $22_{2}^{3}$ and Chang $22_{2}^{2}$ sand bodies are relatively poorly developed, with a channel width of about $500 \mathrm{~m}$. The Chang $2{ }_{1}{ }^{1}$ sand body is relatively best developed among the three small layers of Chang $2{ }_{1}$, with a channel width of $700 \mathrm{~m}$, the sand body of Chang $21^{2}$ is well developed, and the channel width is about $500 \mathrm{~m}$. The sand body of Chang $21^{3}$ is the worst developed, and the channel width is about $450 \mathrm{~m}$.

\section{References}

1. Yang Junjie. Tectonic evolution and oil and gas distribution in the Ordos Basin[M]. Beijing: Petroleum Industry Press. 2000.

2. Wang Guicheng, Ma Weimin, Zhao Hong, Yang Renchao. Sedimentary characteristics of the Triassic Yanchang Formation in Fuxian Exploration Area, Ordos Basin[J]. Journal of Northwest University (Natural Science Edition), 2003. (5): 608-612.

3. Fu Jinhua, Guo Zhengquan, Deng Xiuqin. Upper Triassic Yanchang Formation sedimentary facies and petroleum geological significance in southwestern Ordos Basin[J]. Journal of Palaeogeography, 2005. (1): 34-44.

4. Yang Hua, Liu Xianyang, Zhang Caili, Han Tianyou, Hui Xiao. The main controlling factors and distribution of low-permeability lithologic reservoirs in the Triassic Yanchang Formation in the Ordos Basin[J]. Lithologic Reservoirs, 2007. (3) :1-6.

5. Wang Jianmin, Wu Changrong. The sedimentary characteristics of remote sandy braided rivers in Chang 2+3 oil-bearing group in the eastern part of northern Shaanxi [J]. Minerals and Rocks, 2007. (4): 92-97.

6. Li Wenhou, Pang Jungang, Cao Hongxia, Xiao Li, Wang Ruogu. The Late Triassic Sedimentary System and Lithofacies Paleogeography Evolution in the Late Triassic of Ordos Basin[J]. Journal of Northwest University (Natural Science Edition), 2009.39(3):501 -506 .

7. Guo Chunen, Zuo Yi, Yu Cundong. Application of Sedimentary Microfacies Research Technology in Oilfield Development[J]. Tuha Oil \& Gas, 2006. (3): 230-232, 243

8. Zhao Jingzhou, Yang Xianchao, Wu Fuli, Shi Baohong. On the control of uplift background on the formation and distribution of Triassic reservoirs in the northern Shaanxi slope area of the Ordos Basin[J]. Acta Geology, 2006. (5): 648 -655. 